\title{
Measurement of vapor-liquid equilibria for diethylamine + methanol system represented double azeotropy on elevated pressure
}

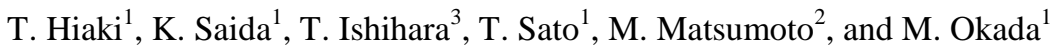 \\ ${ }^{1}$ Department of Applied Molecular Chemistry, College of Industrial Technology, Nihon University, 1-2-1 Izumi-cho, \\ Narashino, Chiba 275-8575 Japan \\ ${ }^{2}$ Liberal Arts and Basic Sciences, College of Industrial Technology, Nihon University, 2-11-1 Shinei, Narashino, Chiba \\ 275-8576 Japan \\ ${ }^{3}$ Kurihalanto Co., Ltd., 1-11-7 Utsubo-honmachi, Nishi-ku, Osaka 550-0004 Japan
}

\section{Introduction}

Accurate phase equilibrium data can be used for the design and operation for separation processes based on phase behavior. An azeotrope is the mixture consists of two or more substances, the equilibrium vapor composition is equivalent to the liquid composition, and the equilibrium temperature (or pressure) indicates extreme value. If the mixture to be separated is an azeotropic system, no separation into pure components can be achieved by simple distillation. Knowledge of the acurate azeotropic data is necessity for chemical process synthesis.

According to the Dortmund Data Bank [1], approximately $47 \%$ of the stored vapor-liquid equilibrium (VLE) data show azeotropic behavior. There are two types of azeotrope for binary systems, which are positive and negative azeotropes, generally. The binary system of diethylamine + methanol is known for the polyazeotropy at given temperature or pressure. The system forms a homogeneous maximum boiling azeotrope at $101.3 \mathrm{kPa}$. The second minimum boiling azeotropic point appears in the VLE at the condition of elevated pressure, around 300 $\mathrm{kPa}$. Aucejo et al. [2] has measured the VLE at 101.3 and $300 \mathrm{kPa}$ and discussed the detail of these phenomena thermodynamically. The purpose of this work is describing the trajectory of two different of azeotropic points on elevated pressure from experimental data.

\section{Experimental}

Experimental apparatus and techniques, mainly developed in our laboratory, for the determination of VLE. The measurements were made in two deferent original equilibrium stills with circulation of both the vapor and liquid phases, equipped with a Cottrell pump. An all-grass VLE still [3], as shown in Figure 1, was used for the measurements at $101.3 \mathrm{kPa}$. The overall charge of the apparatus was about $90 \mathrm{~cm}^{3}$ of the solution. A stainless-steel VLE still with three pressure-tight grass windows (Hiaki et al., unpublished paper) as shown in Figure 2, was used at 405.3 and $506.6 \mathrm{kPa}$. The overall charge of the apparatus was about $120 \mathrm{~cm}^{3}$ of the solution.

Diethylamine and methanol, supplied by the Wako Pure Chemical Co. Ltd. were special grade reagents. The equilibrium composition of the samples was determined using a gas chromatograph (Shinadzu model GC-17A) equipped with a thermal conductivity detector and auto sampler. The column packing was HP-5. The accuracy of liquid, $x i$, and vapor, $y i$, mole fractions is estimated to be 0.002 mole fraction. The temperature was measured with a calibrated platinum resistance thermometer (Automatic System Laboratories model F250) with an accuracy of $0.03 \mathrm{~K}$. The Pressure controller (Druck model DPI520 and RUI 100) was used with an accuracy of $\pm 0.025 \%$ for the range of 1 to 6 bar absolute.

\section{Results and discussion}

Isobaric VLE were measured for the binary system of diethylamine (1) + methanol (2) at 101.3, 405.3 and $506.6 \mathrm{kPa}$. The activity coefficients $\gamma_{i}$ were calculated using the following equation:

$P y_{i}=\gamma_{i} P_{i}^{S} x_{i}$

The vapor pressures of the pure components, $P_{i}^{S}$, were obtained using the Antoine equation constants. The experimental data were tested for thermodynamic consistency by the Van Ness method [4]. The results of consistency test indicate that the VLE data for systems are thermodynamically consistent as shown in Table 1. 
Table 1. Results of consistency test for experimental VLE data.

\begin{tabular}{|c|c|}
\hline Pressure/kPa & $\begin{array}{c}\text { Criterion consistency }(+) \\
\text { Van Ness }(\Delta \mathrm{y} \leq 0.01)\end{array}$ \\
\hline 101.3 & $0.0059(+)$ \\
\hline 405.3 & $0.0060(+)$ \\
\hline 506.6 & $0.0099(+)$ \\
\hline
\end{tabular}

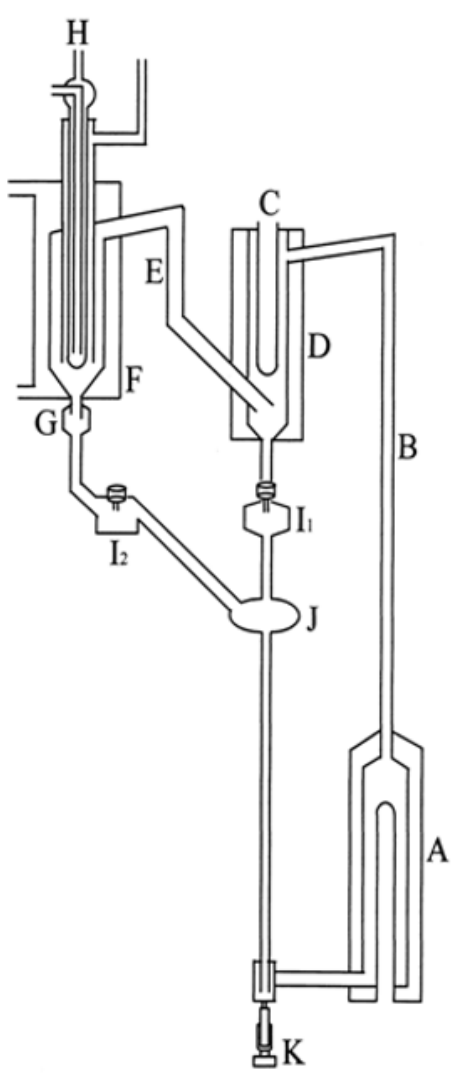

A: Boiling flask

B: Cottrell pump

C: Thermometer well

D: Equilibrium chamber

E: Heater for preventing partial condensation of vapor

F: Condenser

G: Drop counter

$\mathrm{H}$ : To pressure controller or atmosphere

I1, I2: Withdrawal of condensed vapor and liquid sample

$\mathrm{J}$ : Buffer for prevention of backward flow of mixing sample

$\mathrm{K}$ : Drain valve

Figure 1. Schematic diagram of all-grass VLE still.

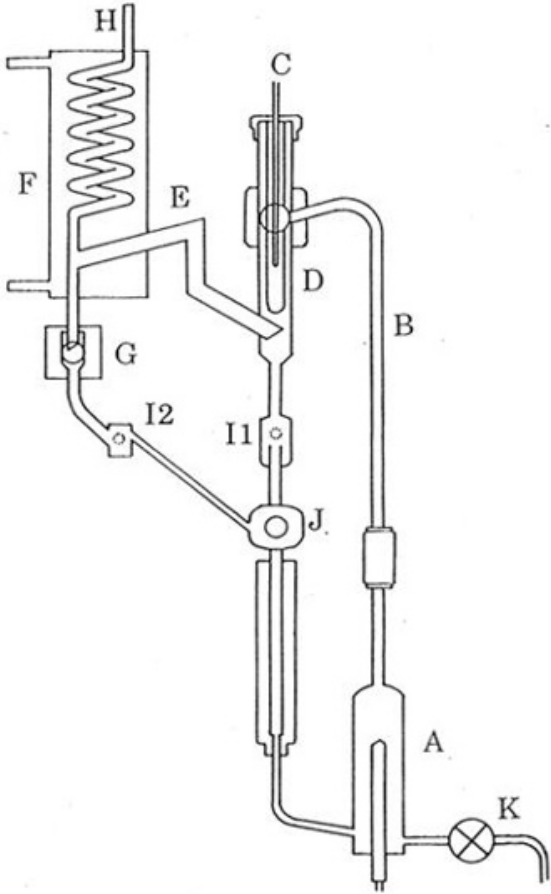
A: Boiling flask
B: Cottrell pump
C: Thermometer well
D: Equilibrium chamber
E: Heater for preventing partial condensation of vapor
F: Condenser
G: Drop counter
$\mathrm{H}$ : To pressure controller or atmosphere
I1, I2: Withdrawal of condensed vapor and liquid sample
$\mathrm{J}$ : Buffer for prevention of backward flow of mixing sample
K: Drain valve

Figure 2. Schematic diagram of VLE still made by SUS-316 


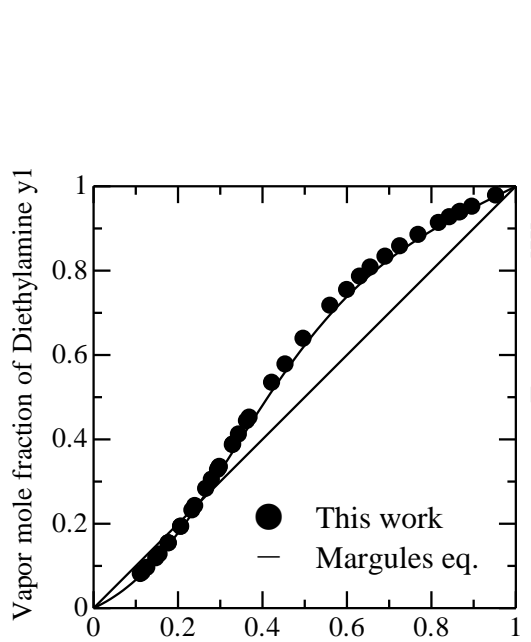

Liquid mole fraction of Diethylamine $\mathrm{x} 1$

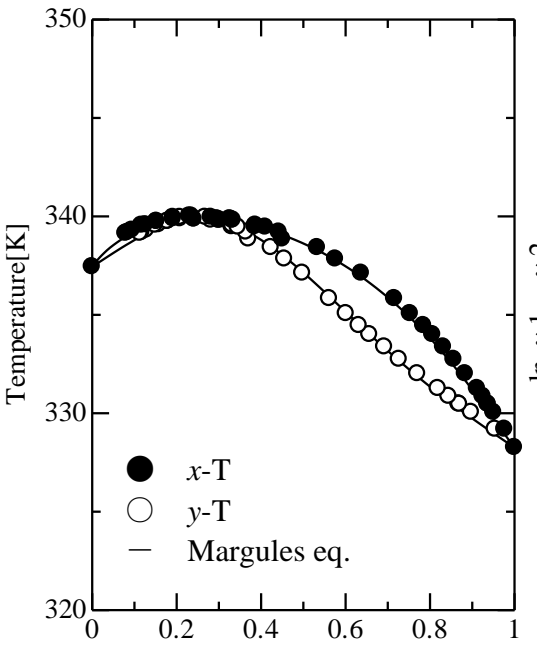

Mole fraction of Diethylamine $\mathrm{x} 1, \mathrm{y} 1$

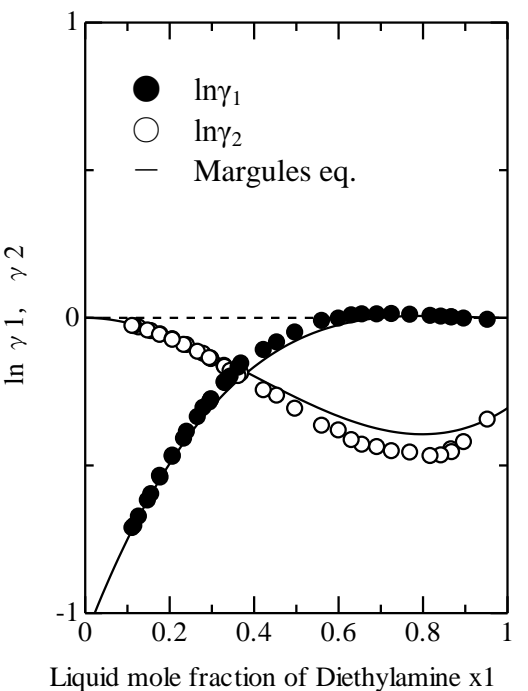

Liquid mole fraction of Diethylamine $\mathrm{x} 1$

Figure 3. VLE diagram for diethylamine (1) + methanol (2) system at $101.3 \mathrm{kPa}$.

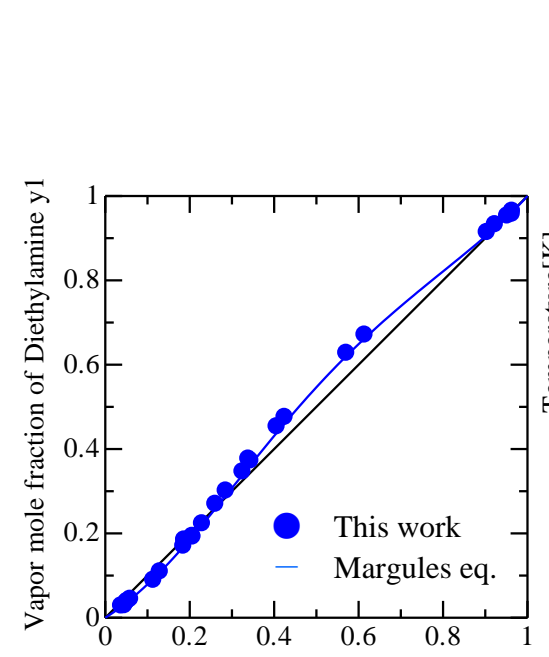

Liquid mole fraction of Diethylamine $\mathrm{x} 1$
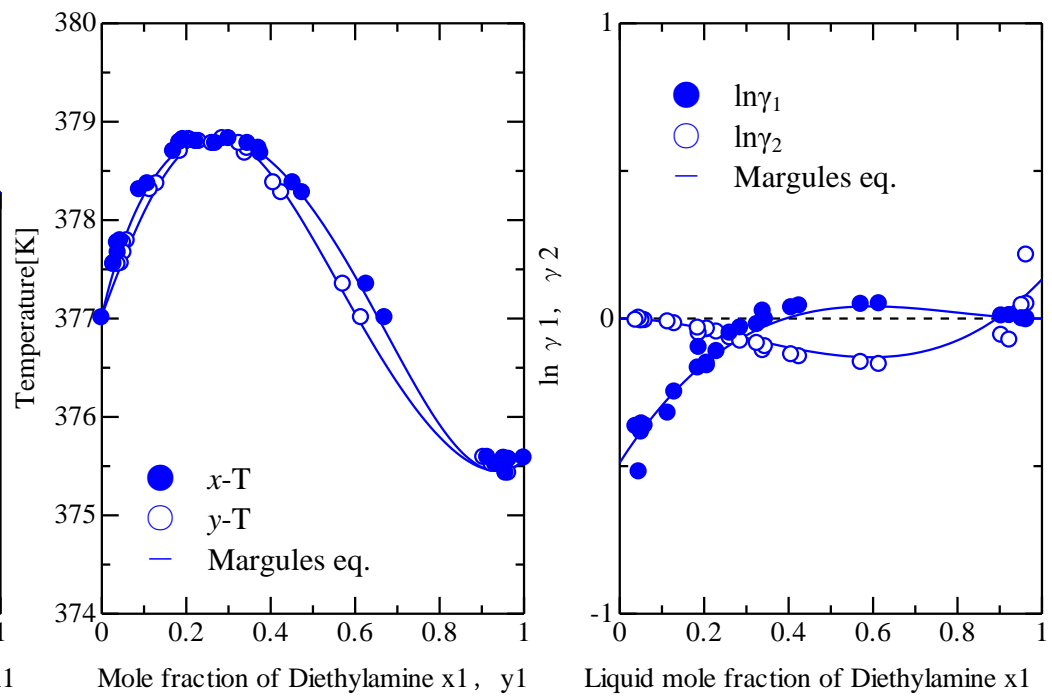

Liquid mole fraction of Diethylamine $\mathrm{x} 1$

Figure 4. VLE diagram for diethylamine (1) + methanol (2) system at $405.3 \mathrm{kPa}$.

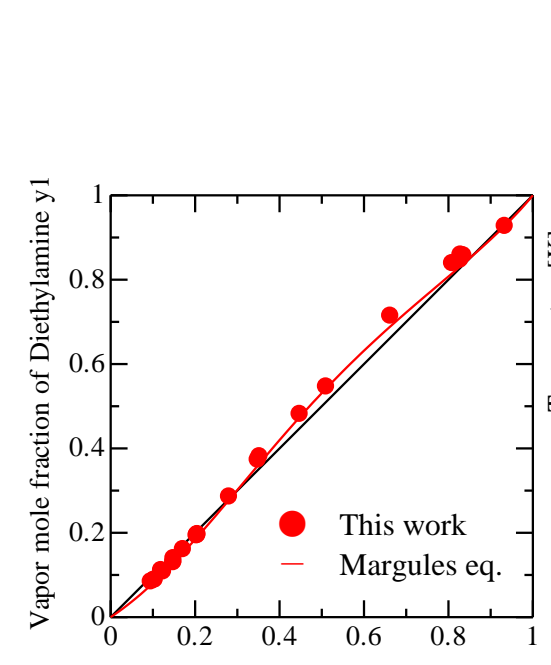

Liquid mole fraction of Diethylamine $\mathrm{x} 1$
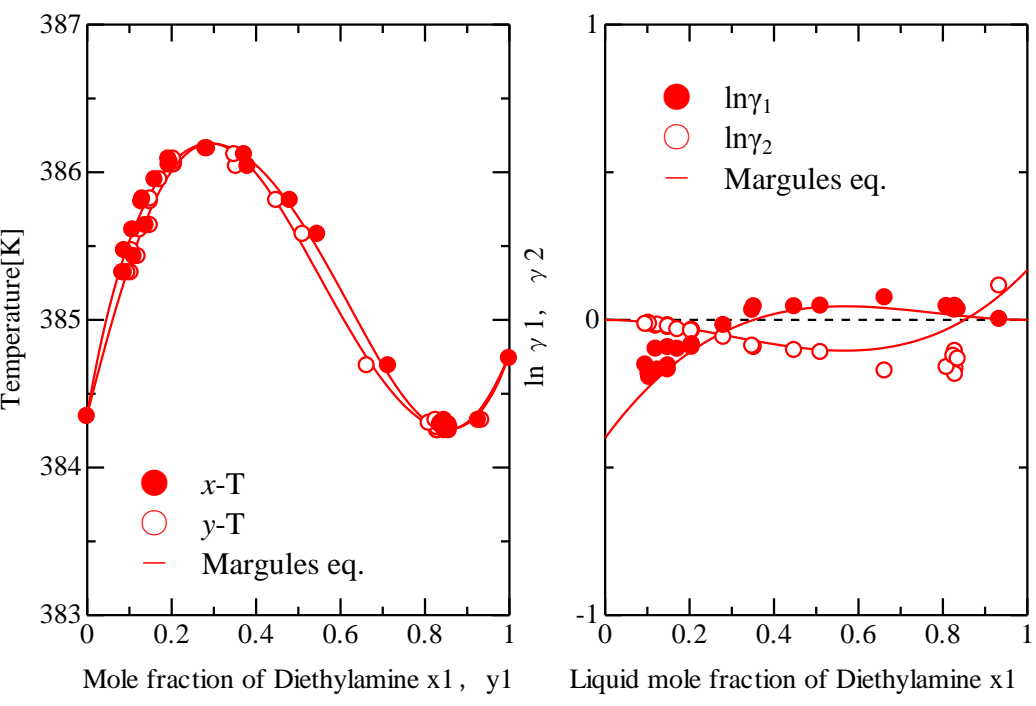

Figure 5. VLE diagram for diethylamine (1) + methanol (2) system at $506.6 \mathrm{kPa}$ 
The experimental VLE data are shown graphically in Figures 3- 5. The system forms a homogeneous maximum boiling azeotrope at $101.3 \mathrm{kPa}$. The second minimum boiling azeotropic point appears in the VLE at the condition of elevated pressure, around $300 \mathrm{kPa}$ [1]. Two azeotropic compositions of both maximum and minimum boiling points change with presented pressure.

The activity coefficients were correlated with the the nonrandom two-liquid (NRTL) [5] and Margules [6] equations. The sum of the squares of relative deviations in activity coefficients was minimized during optimization of the parameters. For the experimental isobaric system of diethylamine (1) + methanol (2) at all pressure condition, the Margules equation yielded the lowest mean deviations between the experimental and calculated activity coefficients. The parameter values and average absolute deviations using the Margules equation are shown in Table 2.

Margules equation:

$$
\begin{aligned}
& \log \gamma_{1}=x_{2}^{2}\left\{A_{12}+2 x_{1}\left(A_{21}-A_{12}\right)\right\} \\
& \log \gamma_{2}=x_{1}^{2}\left\{A_{21}+2 x_{2}\left(A_{12}-A_{21}\right)\right\}
\end{aligned}
$$

Table 2. Margules parameters and deviations between calculated and experimental tenperatures, $\Delta \mathrm{T}$, and vapor phase mole fractions, $\Delta y 1$, for diethylamine (1) + methanol (2) system.

\begin{tabular}{|c|c|c|c|}
\hline \multirow{2}{*}{$\begin{array}{c}\text { Pressure } \\
/ \mathrm{kPa}\end{array}$} & parameters & \multicolumn{2}{|c|}{ average absolute deviation } \\
\cline { 2 - 4 } & $\begin{array}{c}A_{12} / \mathrm{J} \cdot \mathrm{mol}^{-1} \\
A_{21} / \mathrm{J} \cdot \mathrm{mol}^{-1}\end{array}$ & $\Delta \mathrm{T} / \mathrm{K}$ & $\begin{array}{c}\Delta \mathrm{y} 1 \\
/ \mathrm{mol} \text { fract. }\end{array}$ \\
\hline 101.3 & -1.081 & 0.13 & 0.008 \\
& -0.306 & & \\
\hline 405.3 & -0.488 & 0.06 & 0.006 \\
& 0.133 & & \\
\hline 506.6 & -0.400 & 0.05 & 0.010 \\
& 0.169 & & \\
\hline
\end{tabular}

The NRTL equation was not available for the VLE of polyazeotrope. The calculated results are shown by solid lines in Figures 3- 5. The azeotropic data, which were determined on the basis of the experimental data, are shown in Table 3 and Figure 6.
Table 3. Azeotropic data for diethylamine (1) + methanol (2) at each experimental pressure: $\mathrm{T}_{\mathrm{az} 1}$ and $\mathrm{x}_{1 \mathrm{az} 1}$, maximum boiling azeotropic data; $\mathrm{T}_{\mathrm{az} 2}$ and $\mathrm{x}_{1 \mathrm{az} 1}$, minimum boiling azeotropic data.

\begin{tabular}{|c|c|c|c|c|}
\hline \multirow{2}{*}{$\begin{array}{c}\text { Pressure } \\
/ \mathrm{kPa}\end{array}$} & \multicolumn{4}{|c|}{ Azeotropic Data } \\
\cline { 2 - 5 } & $\mathrm{T}_{\mathrm{az} 1} / \mathrm{K}$ & $\begin{array}{c}\mathrm{x}_{\text {laz1 }} \\
/ \mathrm{mol} \text { fract. }\end{array}$ & $\mathrm{T}_{\mathrm{az} 2} / \mathrm{K}$ & $\begin{array}{c}\mathrm{x}_{1 \mathrm{az} 2} \\
/ \mathrm{mol} \text { fract. }\end{array}$ \\
\hline 101.3 & 339.9 & 0.242 & no & no \\
\hline $300.0^{2)}$ & 369.9 & 0.250 & 363.8 & 0.985 \\
\hline 405.3 & 378.8 & 0.259 & 375.5 & 0.954 \\
\hline 506.6 & 386.2 & 0.282 & 384.3 & 0.863 \\
\hline
\end{tabular}

Two azeotropic compositions of both maximum and minimum boiling points change with presented pressure. Acording to the Arrenius prots of $\ln \mathrm{P}$ vs. $1 / \mathrm{T}_{\mathrm{az}}$, the azeotropic points of this system will be estimated to disappear at the pressure of around $0.7 \mathrm{MPa}$.

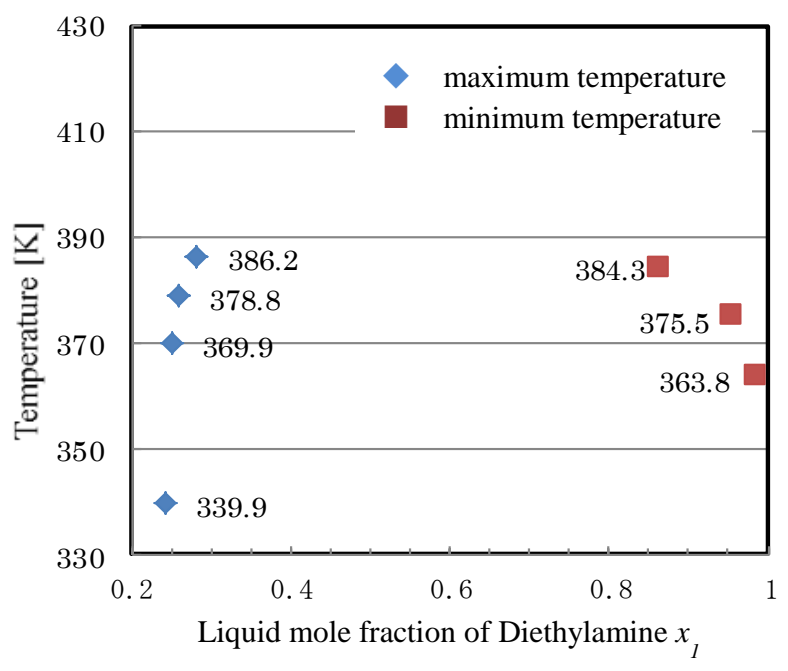

Figure 6. Azeotropic data for diethylamine (1) + methanol (2) at $101.3,300.0,405.3$, and $506.6 \mathrm{kPa}$.

\section{References}

1. J. Gmehling, J. Menke, J. Krafczyk, K. Fischer, Azeotropic Data,VCH Publishers, Inc. New York, 1994

2. A. Aucejo. S. Loras, R. Munoz, J. Wisniak, H. Segura, J. Chem. Eng. Data 421201 (1997)

3. T. Haiki, K. Yamato, K. Kojima, J. Chem. Eng. Data 37203 (1992)

4. H.C. Van Ness, S.M. Byer, R.E. Gibbs, AIChE J. 19 238 (1973)

5. H. Renon, J.M. Prausnitz, AIChE J. 14135 (1968)

6. M. Margules, Sitzgber Acad. Wiss. Wien 1041243 (1895) 